Journal of Patient-Centered

\title{
Prevalence of Infectious Diseases Among 6078 Individuals With Down Syndrome in the United States
}

\author{
Veronica Fitzpatrick \\ Anne Rivelli \\ Sagar Chaudhari \\ Laura Chicoine \\ Gengjie Jia \\ Andrey Rzhetsky \\ Brian Chicoine
}

Follow this and additional works at: https://aah.org/jpcrr

Part of the Bacterial Infections and Mycoses Commons, Clinical Epidemiology Commons,

Environmental Public Health Commons, Family Medicine Commons, Health Services Research Commons, Infectious Disease Commons, Internal Medicine Commons, Medical Immunology Commons, Primary Care Commons, and the Virus Diseases Commons

\section{Recommended Citation}

Fitzpatrick V, Rivelli A, Chaudhari S, Chicoine L, Jia G, Rzhetsky A, Chicoine B. Prevalence of infectious diseases among 6078 individuals with Down syndrome in the United States. J Patient Cent Res Rev. 2022;9:64-9. doi: 10.17294/2330-0698.1876

Published quarterly by Midwest-based health system Advocate Aurora Health and indexed in PubMed Central, the Journal of Patient-Centered Research and Reviews (JPCRR) is an open access, peer-reviewed medical journal focused on disseminating scholarly works devoted to improving patient-centered care practices, health outcomes, and the patient experience. 


\title{
Prevalence of Infectious Diseases Among 6078 Individuals With Down Syndrome in the United States
}

\author{
Veronica Fitzpatrick, DrPH, ${ }^{1,2}$ Anne Rivelli, MA, MPH, ${ }^{1,2}$ Sagar Chaudhari, MA, ${ }^{3}$ Laura Chicoine, BA, ${ }^{1,4}$ \\ Gengjie Jia, PhD, ${ }^{5}$ Andrey Rzhetsky, $\mathrm{PhD},{ }^{5}$ Brian Chicoine, $\mathrm{MD}^{1,4}$ \\ ${ }^{1}$ Advocate Aurora Health, Downers Grove, IL; ${ }^{2}$ Advocate Aurora Research Institute, Downers Grove, IL; ${ }^{3}$ Chicago \\ Medical School, Rosalind Franklin University of Medicine and Science, North Chicago, IL; ${ }^{4}$ Advocate Medical Group \\ Adult Down Syndrome Center, Park Ridge, IL; ${ }^{5}$ University of Chicago, Chicago, IL
}

\begin{abstract}
A recent disease prevalence study of the largest documented Down syndrome (DS) cohort in the United States strongly suggested significant disparity in general infectious disease conditions among individuals with DS versus those without DS. In this follow-up retrospective analysis, we explored these differences in greater detail by calculating prevalence of 52 infectious diseases, across 28 years of data among 6078 individuals with DS and 30,326 age- and sex-matched controls, abstracted from electronic medical records within a large Midwestern health system.

We found that the DS cohort had higher prevalence of pneumonias (including aspiration, viral, bacterial, pneumococcal, and unspecified/atypical); otitis externa; and the skin infections impetigo, abscess, and cellulitis. To the contrary, the DS cohort had lower prevalence of many respiratory infections other than pneumonia (including influenza, strep pharyngitis, upper respiratory infection, sinusitis, tonsillitis, laryngitis, bronchitis, scarlet fever, and otitis media); sexually transmitted infections (including bacterial vaginosis, chlamydia, genital herpes, HIVIAIDS, human papillomavirus, pelvic inflammatory disease, and trichomoniasis); mononucleosis; shingles; unspecified hepatitis; intestinal infections; and enteritis. These findings highlight that individuals with DS could be more or less prone to different infectious diseases than their non-DS matched counterparts. Additional research to understand why these differences exist and how they might affect the clinical approach to patients with DS is warranted. (J Patient Cent Res Rev. 2022;9:64-69.)
\end{abstract}

Keywords Down syndrome; prevalence; infectious disease; pneumonia; skin; influenza; sinusitis; bronchitis; STI

A recent study of the largest documented cohort of individuals with Down syndrome (DS) in the nited States described the prevalence of a broad range of disease conditions. ${ }^{1}$ Findings strongly suggested a particularly significant disparity in infectious disease among individuals with DS when compared with ageand sex-matched individuals without DS. ${ }^{1}$

Individuals with DS may be particularly vulnerable to infectious diseases due to factors that increase risk of contracting infections, including an impaired immune system, an accelerated aging process, and structural abnormalities. ${ }^{2-6}$ Reduced T- and B-cell counts, a smaller thymus size, subpar antibody response to vaccinations, and decreased chemotaxis seen in individuals with DS

Corresponding author: Anne Rivelli,

Advocate Lutheran General Hospital, 1775 Dempster St., Suite W-939, Park Ridge, IL 60068 (anne.rivelli@aah.org) contribute to their decreased immune response. ${ }^{2}$ It is well known that pneumonias are widespread in adults with DS, with increased hospitalization and mortality; however, other infectious disease prevalences are less known. ${ }^{2-9}$

While it has been reported that individuals with DS have lower prevalence of sexually transmitted infections (STIs) than the general population; ${ }^{10}$ very little research has gone into characterizing STIs in children and adults with DS. In the general population, chlamydia, gonorrhea, and syphilis have been on the rise for the past several years, ${ }^{11}$ further warranting an examination into STI rates in the DS population to better guide sex education guidelines. Given that prevalence of DS itself is increasing ${ }^{4}$ and that the lifespan for individuals with DS continues to grow, ${ }^{3-7}$ diving further into the specific infections unique to this population is critical to best tailor care.

Herein, this study utilized clinical data representing the largest reported sample of individuals with DS in the United States, treated across a single Midwestbased integrated health system that includes the largest 
center of DS care for adolescents and adults, to explore infection prevalences among those diagnosed with DS. Learning critical information on the most common infectious diseases seen in these individuals might serve to better guide practitioners in their attempts to provide patient-centered care.

\section{METHODS}

This retrospective, descriptive cohort study, which utilized 28 years of available encounter data (May 1991-September 2019) abstracted from electronic medical records collected from all sites within one of the largest nonprofit health systems in the United States, was determined to be non-human subjects research by the institutional review board. Full details on the data collection methods for this overall study population can be found in the previously published parent report. ${ }^{1}$

\section{Participants}

A total of 6078 cases, deemed eligible for inclusion based on having at least 1 encounter with an International Classification of Diseases (ICD) code of DS, were identified. Comparable control patients included up to 5 individuals without a diagnosis of DS who were matched to each case on year of birth ( \pm 1 year) and sex by a data analyst. This approach resulted in 30,326 eligible controls. Of the 6078 cases, 64 were assigned only 4 (as opposed to 5) matched controls.

\section{Procedures}

This study design preidentified specific infectious disease conditions of interest to assess prevalence among individuals with DS versus those without. Conditions were chosen based on existing literature and the clinical expertise of one of the authors (B.C.). This study used the U.S. Clinical Modification (CM) codes for medical diagnoses based on the statistical classification of disease denoted in the World Health Organization's publication of the ICD. ${ }^{12}$ Specifically, 10th Revision (ICD-10-CM) and 9th Revision (ICD-9-CM) codes were used. A few conditions of interest did not align clearly with ICD9-CM codes and, instead, AHRQ CCS categories were used. See Table 1 for a complete list of infectious disease conditions of interest and associated ICD codes.

\section{Statistical Methods}

Demographics are reported as means with standard deviations and medians with ranges for age and total encounters per sample. Sex, race, ethnicity, and insurance type are reported as counts with percentages. Clinical conditions are reported as counts with percentages and odds ratios (OR) representing the odds of cases having an infectious disease relative to controls. Corresponding Pearson's chi-squared P-values represent statistically significant differences (at an alpha of $<0.05$ ) in prevalence of diagnoses between cases and controls. Fisher's exact P-value was interpreted when any sample count was less than 5 .

\section{RESULTS}

The DS case population was predominantly White (77.35\%) and of non-Hispanic/Latino ethnicity (73.51\%). Cases had a median of 6 total encounters (ie, clinical visits in the health system) in the dataset. The control cohort was also predominantly White $(61.97 \%)$ and of non-Hispanic/Latino ethnicity $(81.72 \%)$, with a median of 7 total encounters in the dataset. Both groups were approximately $52 \%$ male and had a median age of 25 years. For complete demographics of the DS and matched control cohorts, the reader is referred to the relevant table published within this project's parent article. ${ }^{1}$

The following paragraphs highlight statistically significant ORs $(95 \% \mathrm{CI})$ and $\mathrm{P}$-values that were derived from comparing prevalence of clinical infectious disease conditions of interest among individuals with DS (ie, cases) to matched controls. Table 2 shows both significant and nonsignificant analysis results.

Relative to controls, individuals with DS had significantly greater odds of experiencing any pneumonia (OR: 4.13 $[3.74,4.56] ; \mathrm{P}<0.0001)$ and, specifically, aspiration (OR: 10.50 [7.73, 14.28]; $\mathrm{P}<0.0001$ ), viral (OR: 13.14 [8.12, $21.26] ; \mathrm{P}<0.0001$ ), bacterial (OR: 4.72 [3.52, 6.33]; $\mathrm{P}<0.0001$ ), pneumococcal (OR: 6.87 [2.76, 17.09]; $\mathrm{P}<0.0001$ ), and unspecified or atypical pneumonia (OR: $3.69[3.31,4.11] ; \mathrm{P}<0.0001)$. The DS cohort also had more frequent otitis externa (OR: 1.68 [1.42, 1.98]; $\mathrm{P}<0.0001)$ and one or more of the skin infections impetigo, abscess, and cellulitis (OR: 1.74 [1.62, 1.88]; $\mathrm{P}<0.0001)$.

Conversely, relative to controls, individuals with DS had lesser odds of experiencing the following infectious diseases: influenza (OR: 0.62 [0.52, 0.75]; $\mathrm{P}<0.0001$ ); streptococcal pharyngitis (OR: $0.27[0.22$, 0.33 ; $\mathrm{P}<0.0001)$; upper respiratory infection (OR: 0.37 [0.34,0.40]; $\mathrm{P}<0.0001$ ); sinusitis (OR: 0.38 [0.34, 0.42]; $\mathrm{P}<0.0001$ ); tonsillitis (OR: 0.58 [0.51, 0.65]; $\mathrm{P}<0.0001$ ); laryngitis (OR: $0.81[0.68,0.97] ; \mathrm{P}=0.0218)$; bronchitis (OR: $0.48[0.42,0.56] ; \mathrm{P}<0.0001$ ); scarlet fever (OR: $0.36[0.17,0.78] ; \mathrm{P}=0.0070$ ); otitis media (OR: 0.77 $[0.70,0.85] ; \mathrm{P}<0.0001)$; and the STIs bacterial vaginosis (OR: 0.14 [0.10, 0.19]; $\mathrm{P}<0.0001$ ), chlamydia (OR: 0.07 [0.01, 0.53]; $\mathrm{P}<0.0001$ ), genital herpes (OR: 0.08 [0.03, 0.21 ; $\mathrm{P}<0.0001$ ), HIV/AIDS (OR: 0.31 [0.13, 0.77]; $\mathrm{P}=0.0074$ ), human papillomavirus (OR: $0.35[0.21$, 0.59]; $\mathrm{P}<0.0001$ ), pelvic inflammatory disease (OR: 0.29 $[0.12,0.72] ; \mathrm{P}=0.0045$ ), and trichomoniasis (OR: 0.08 
Table 1. Infectious Disease Conditions of Interest and Associated Codes

\begin{tabular}{|c|c|c|}
\hline Infection type & ICD-10-CM code & ICD-9-CM or AHRQ ${ }^{24}$ code \\
\hline \multicolumn{3}{|l|}{ Respiratory } \\
\hline Coronaviruses (excludes COVID-19) & B342 & 07989 \\
\hline Diphtheria & A36 & 032 \\
\hline Influenza & J09-J11 & AHRQ 123 \\
\hline Haemophilus influenzae type B & A492 & 0415 \\
\hline Measles & B05 & 055 \\
\hline Mumps & B26 & 0727-0729 \\
\hline Rubella (German measles) & B06 & 056 \\
\hline Whooping cough (pertussis) & A37 & 033 \\
\hline Strep pharyngitis & J020 & 0340 \\
\hline Upper respiratory infection & J069 & 4659 \\
\hline Sinusitis & J01, J32 & 461,473 \\
\hline Tonsillitis & $\mathrm{J} 03, \mathrm{~J} 35$ & $463,47400-47402$ \\
\hline Laryngitis & J04-J05, J37 & 4640,4760 \\
\hline Bronchitis & $\mathrm{J} 20$ & AHRQ 125, 490, 49122 \\
\hline Scarlet fever & A38 & 0341 \\
\hline Otitis media & H669 & 3829 \\
\hline Pneumonia & $\mathrm{J} 12-\mathrm{J} 15, \mathrm{~J} 18, \mathrm{~J} 690$ & AHRQ 122 \\
\hline Aspiration & $\mathrm{J} 12-\mathrm{J} 15, \mathrm{~J} 18, \mathrm{~J} 690$ & AHRQ 122 \\
\hline Viral & $\mathrm{J} 12$ & 4809 \\
\hline Bacterial & $\mathrm{J} 15$ & 4829 \\
\hline H. influenzae-caused & $\mathrm{J} 14$ & 4822 \\
\hline Pneumococcal & $\mathrm{J} 13$ & 481 \\
\hline Unspecified/Atypical & J18, J690 & 486,5070 \\
\hline \multicolumn{3}{|l|}{ Sexually transmitted } \\
\hline Bacterial vaginosis & N76 & 61610 \\
\hline Chlamydia & A55-A56 & 07988,07998 \\
\hline Gonorrhea & A54 & 098 \\
\hline Genital herpes & A60 & 0541 \\
\hline HIVIAIDS & B20 & AHRQ 5 \\
\hline Human papillomavirus & R8781-R8782 & 0794 \\
\hline Pelvic inflammatory disease & A1817, A5424, A5611, N73, N74 & 614 \\
\hline Syphilis & A50-A53 & 090-097 \\
\hline Trichomoniasis & A59 & 131 \\
\hline Urinary tract infection & N398 & 5990 \\
\hline \multicolumn{3}{|l|}{ Other infection } \\
\hline Otitis externa & $\mathrm{H} 609$ & 38010 \\
\hline Infectious mononucleosis & $\mathrm{B} 27$ & 075 \\
\hline Zika & A925 & 0663 \\
\hline Shingles (Herpes zoster) & B02 & 053 \\
\hline Tetanus (lockjaw) & A35 & 037 \\
\hline Norovirus & A0811 & 00863 \\
\hline Polio & A80 & 045 \\
\hline Meningococcal disease & A390, A3950-A3953, A3981-A3984, A3989, A399 & 036 \\
\hline Hepatitis & B15-B19 & AHRQ 6 \\
\hline Hepatitis A & B15 & - \\
\hline Hepatitis B, acute & B16 & - \\
\hline Other acute hepatitis & B17 & - \\
\hline Chronic viral hepatitis & B18 & - \\
\hline Unspecified hepatitis & B19 & - \\
\hline Ebola & A984 & 0658, 07889 \\
\hline Skin infections (impetigo, abscess, cellulitis) & L00-L039, L08 & AHRQ 197, 684 \\
\hline Intestinal infections & A08-A09 & AHRQ 135 \\
\hline Enteritis & K529 & 5589 \\
\hline Lyme disease & A6920 & 08881 \\
\hline
\end{tabular}

AHRQ, Agency for Healthcare for Research and Quality; CM, Clinical Modifications; ICD, International Classification of Diseases. 
Table 2. Prevalence of Infectious Conditions of Interest Among Cases vs Controls

\begin{tabular}{|c|c|c|c|c|}
\hline Infection type & $\begin{array}{c}\text { DS sample } \\
(\mathrm{n}=6078)\end{array}$ & $\begin{array}{c}\text { Controls } \\
(n=30,326)\end{array}$ & OR $(95 \% \mathrm{Cl})$ & $P^{a}$ \\
\hline \multicolumn{5}{|l|}{ Respiratory } \\
\hline Coronaviruses (excludes COVID-19) & 0 & 1 & - & $1.0000^{b}$ \\
\hline Diphtheria & 0 & 0 & - & - \\
\hline Influenza & 128 & 1010 & $0.62(0.52,0.75)$ & $<0.0001$ \\
\hline Haemophilus influenzae type B & 0 & 0 & - & - \\
\hline Measles & 3 & 3 & $4.99(1.01,24.74)$ & $0.0626^{b}$ \\
\hline Mumps & 0 & 6 & - & $0.5981^{b}$ \\
\hline Rubella (German measles) & 2 & 2 & $4.99(0.70,35.44)$ & $0.1323^{b}$ \\
\hline Whooping cough (pertussis) & 1 & 19 & $0.26(0.04,1.96)$ & $0.2321^{b}$ \\
\hline Strep pharyngitis & 116 & 2027 & $0.27(0.22,0.33)$ & $<0.0001$ \\
\hline Upper respiratory infection & 756 & 8384 & $0.37(0.34,0.40)$ & $<0.0001$ \\
\hline Sinusitis & 387 & 4616 & $0.38(0.34,0.42)$ & $<0.0001$ \\
\hline Tonsillitis & 314 & 2624 & $0.58(0.51,0.65)$ & $<0.0001$ \\
\hline Laryngitis & 148 & 902 & $0.81(0.68,0.97)$ & 0.0218 \\
\hline Bronchitis & 236 & 2334 & $0.48(0.42,0.56)$ & $<0.0001$ \\
\hline Scarlet fever & 7 & 96 & $0.36(0.17,0.78)$ & 0.0070 \\
\hline Otitis media & 564 & 3541 & $0.77(0.70,0.85)$ & $<0.0001$ \\
\hline Pneumonia & 746 & 993 & $4.13(3.74,4.56)$ & $<0.0001$ \\
\hline Aspiration & 126 & 61 & $10.50(7.73,14.28)$ & $<0.0001$ \\
\hline Viral & 60 & 23 & $13.14(8.12,21.26)$ & $<0.0001$ \\
\hline Bacterial & 87 & 93 & $4.72(3.52,6.33)$ & $<0.0001$ \\
\hline H. influenzae-caused & 11 & 8 & $6.87(2.76,17.09)$ & $<0.0001$ \\
\hline Pneumococcal & 2 & 0 & - & $0.0279^{b}$ \\
\hline Unspecified/Atypical & 596 & 868 & $3.69(3.31,4.11)$ & $<0.0001$ \\
\hline \multicolumn{5}{|l|}{ Sexually transmitted } \\
\hline Bacterial vaginosis & 32 & 1128 & $0.14(0.10,0.19)$ & $<0.0001$ \\
\hline Chlamydia & 1 & 68 & $0.07(0.01,0.53)$ & $<0.0001^{\mathrm{b}}$ \\
\hline Gonorrhea & 7 & 55 & $0.63(0.29,1.39)$ & 0.2533 \\
\hline Genital herpes & 4 & 255 & $0.08(0.03,0.21)$ & $<0.0001^{\text {b }}$ \\
\hline HIVIAIDS & 5 & 80 & $0.31(0.13,0.77)$ & 0.0074 \\
\hline Human papillomavirus & 16 & 224 & $0.35(0.21,0.59)$ & $<0.0001$ \\
\hline Pelvic inflammatory disease & 5 & 85 & $0.29(0.12,0.72)$ & 0.0045 \\
\hline Syphilis & 5 & 45 & $0.55(0.22,1.40)$ & 0.2039 \\
\hline Trichomoniasis & 1 & 62 & $0.08(0.01,0.58)$ & $0.0003^{b}$ \\
\hline Urinary tract infection & 2 & 25 & $0.40(0.09,1.68)$ & $0.2992^{b}$ \\
\hline \multicolumn{5}{|l|}{ Other infection } \\
\hline Otitis externa & 193 & 582 & $1.68(1.42,1.98)$ & $<0.0001$ \\
\hline Infectious mononucleosis & 8 & 124 & $0.32(0.16,0.66)$ & 0.0010 \\
\hline Zika & 0 & 0 & - & - \\
\hline Shingles (Herpes zoster) & 17 & 322 & $0.26(0.16,0.43)$ & $<0.0001$ \\
\hline Tetanus (lockjaw) & 0 & 1 & - & $1.0000^{b}$ \\
\hline Norovirus & 2 & 3 & $3.33(0.56,19.92)$ & $0.1968^{b}$ \\
\hline Polio & 0 & 3 & - & $1.0000^{\mathrm{b}}$ \\
\hline Meningococcal disease & 0 & 0 & - & - \\
\hline Hepatitis & 42 & 189 & $1.11(0.79,1.55)$ & 0.5435 \\
\hline Hepatitis A & 4 & 12 & $1.66(0.54,5.16)$ & $0.3257^{b}$ \\
\hline Hepatitis B, acute & 4 & 19 & $1.05(0.36,3.09)$ & $1.0000^{b}$ \\
\hline Other acute hepatitis & 1 & 6 & $0.83(0.10,6.91)$ & $1.0000^{b}$ \\
\hline Chronic viral hepatitis & 26 & 120 & $1.08(0.71,1.65)$ & 0.7180 \\
\hline Unspecified hepatitis & 6 & 75 & $0.40(0.17,0.92)$ & 0.0248 \\
\hline Ebola & 0 & 0 & - & - \\
\hline Skin infections (impetigo, abscess, cellulitis) & 1035 & 3201 & $1.74(1.62,1.88)$ & $<0.0001$ \\
\hline Intestinal infections & 65 & 639 & $0.50(0.39,0.65)$ & $<0.0001$ \\
\hline Enteritis & 131 & 1277 & $0.50(0.42,0.60)$ & $<0.0001$ \\
\hline Lyme disease & 4 & 16 & $1.25(0.42,3.73)$ & $0.7622^{\mathrm{b}}$ \\
\hline
\end{tabular}

aStatistical significance was reached at an alpha of $<0.05$.

${ }^{b}$ Fisher's exact test $P$-value was interpreted due to low sample count.

DS, Down syndrome; OR, odds ratio. 
$[0.01,0.58] ; \mathrm{P}=0.0003)$. The DS cohort also had less frequently diagnosed infectious mononucleosis (OR: $0.32[0.16,0.66] ; \mathrm{P}=0.0010$ ); shingles (OR: 0.26 [0.16, $0.43] ; \mathrm{P}=0.0248$ ); unspecified hepatitis (OR: 0.40 [0.17, 0.92]; $\mathrm{P}=0.0248)$; intestinal infection (OR: 0.50 [0.39, $0.65]$; $\mathrm{P}<0.0001$ ); and enteritis (OR: 0.50 [0.42, 0.60]; $\mathrm{P}<0.0001)$.

\section{DISCUSSION}

Generally, our findings support similar data of this range and magnitude available from previous research. ${ }^{13}$ Individuals with DS had lower prevalence of most respiratory infections but, consistent with other findings, higher prevalence of the more severe infections of pneumonia. ${ }^{14-16}$ Immune defects and airway anatomical abnormalities, and an inability to handle secretions, have been noted to explain increased infections among individuals with DS. ${ }^{14}$ Furthermore, encounter-level provider documentation habits could explain discrepancies; specifically, if a condition that may be assessed as more severe (eg, pneumonia) or as a complication of an initial infection is diagnosed, then less severe or initial conditions (eg, influenza, sinusitis, laryngitis) may be left undocumented.

Specific to STIs, individuals with DS in our study had lower prevalence, most to a statistically significant degree, which could be due to less sexual activity contributed to by noted delays in sexual maturity. ${ }^{17}$ Overall, there are limited data on sexual activity of individuals with intellectual disabilities, including individuals with DS, as data are often reported by caregivers rather than the individual with DS and providers are less likely to test this population based on perceived risk, potentially further affecting findings. ${ }^{18-20}$

Recent research among ambulatory and hospitalized adults with DS concluded that, despite an overall low rate of infections among ambulatory patients, hospitalized adults were mostly admitted for infections and that infections were associated with neurological degeneration and increased mortality. ${ }^{21}$ Furthermore, specific to the COVID-19 virus, the small group of individuals with DS hospitalized for COVID-19 displayed more severe cases than controls, particularly an increased incidence of sepsis and mechanical ventilation. ${ }^{22}$ Additional research to understand unique prevalence of varying infections and subsequent unique effects on individuals with DS is necessary.

\section{Strengths/Limitations}

Our DS cohort is one of the largest to date, making it suitable for the analysis of relatively rare morbidities of interest. Incorporating the earliest available patient data, which represented a 28-year span, allowed for a comprehensive look at prevalence. Our analysis also included a large group of controls matched by age and sex, a sample that can be viewed as representative of a U.S. patient population without DS. Differences in race, ethnicity, and insurance should be noted, as these differences may have been contributors to or effects of findings, or both.

While findings represent data from only a single health system, such a large system may provide the most accurate and available review of prevalence nationally, given the United States' fragmented storage of patient data. Furthermore, much of the dataset was drawn from a specialized care center specifically serving adults with DS, which may improve diagnostic accuracy of ICD coding and subsequent prevalence findings. A minority of data came from other nonspecialized system sites less familiar with serving adults with DS, potentially affecting diagnostic consistency. It should be noted that diagnostic accuracy in general can be difficult with individuals with DS for a variety of reasons. ${ }^{23}$ While the conditions of interest in this study incorporated an established coding framework of ICD codes $^{24}$ and were carefully chosen and reviewed by a physician who specializes in treating DS, it must be acknowledged that the utilized codes may not be ones most commonly used to diagnose conditions among patients with DS, introducing the potential for underrepresentation of conditions. It is also possible that these codes could over- or underrepresent diagnoses among individuals with DS relative to those without DS.

This study looked at all individuals with DS, including youth and adults, and reported prevalence of conditions among them relative to controls. Future longitudinal analyses are necessary to look at conditions across time, to report on youth and adults separately, and to track the course of conditions seen at different life stages of individuals with DS, particularly as the average lifespan continues to increase.

\section{CONCLUSIONS}

This follow-up report to a previously published general prevalence study among individuals with Down syndrome $^{1}$ drills down specifically into infectious diseases. Among one of the largest known DS cohorts with matching controls in the United States, diagnosis of numerous infectious disease conditions significantly differed between those with and without DS. In particular, pneumonias were more prevalent and sexually transmitted infections less prevalent in individuals with DS. Findings can be used to better inform and guide both primary and specialized practitioners in the screening and treatment of this unique patient population. 


\section{Patient-Friendly Recap}

- Authors used longitudinal data from patient records at a single health system to compare rates of relatively common infectious diseases in those with Down syndrome (DS) versus a control cohort of similar patients without DS, documenting diagnosis of infections as more or less prevalent.

- Individuals with DS were significantly more likely to have pneumonias and skin infections and less likely to have most other respiratory (eg, influenza, bronchitis, sinusitis) or sexually transmitted infections than their age- and sex-matched counterparts.

- Differing infectious disease prevalences can be used to guide primary and specialized practitioners in the screening, diagnosis, and care of people with DS.

\section{Author Contributions}

Study design: Fitzpatrick, Rivelli, Jia, Rzhetsky, B. Chicoine. Data acquisition or analysis: Fitzpatrick, Rivelli, Chaudhari, L. Chicoine, B. Chicoine. Manuscript drafting: Fitzpatrick, Rivelli, Chaudhari, L. Chicoine, B. Chicoine. Critical revision: Fitzpatrick, Rivelli, Chaudhari, L. Chicoine, B. Chicoine.

\section{Conflicts of Interest}

None.

\section{Funding Sources}

This work was funded in part by a National Institutes of Health award (\#3UL1TR002389-03S1).

\section{References}

1. Chicoine B, Rivelli A, Fitzpatrick V, Chicoine L, Jia G, Rzhetsky A. Prevalence of common disease conditions in a large cohort of individuals with Down syndrome in the United States. J Patient Cent Res Rev. 2021;8:86-97. CrossRef

2. Glasson EJ, Sullivan SG, Hussain R, Petterson BA, Montgomery PD, Bittles AH. The changing survival profile of people with Down's syndrome: implications for genetic counselling. Clin Genet. 2002;62:390-3. CrossRef

3. Zhu JL, Hasle H, Correa A, et al. Survival among people with Down syndrome: a nationwide population-based study in Denmark. Genet Med. 2013;15:64-9. CrossRef

4. Mai CT, Isenburg JL, Canfield MA, et al. National populationbased estimates for major birth defects, 2010-2014. Birth Defects Res. 2019;111:1420-35. CrossRef

5. Capone GT, Chicoine B, Bulova P, et al. Co-occurring medical conditions in adults with Down syndrome: a systematic review toward the development of health care guidelines. Am J Med Genet A. 2018;176:116-33. CrossRef

6. Capone G, Stephens M, Santoro S, et al. Co-occurring medical conditions in adults with Down syndrome: a systematic review toward the development of health care guidelines. Part II. Am J Med Genet A. 2020;182:1832-45. CrossRef

7. Bittles AH, Bower C, Hussain R, Glasson EJ. The four ages of Down syndrome. Eur J Public Health. 2007;17:221-5. CrossRef
8. Alexander M, Petri H, Ding Y, Wandel C, Khwaja O, Foskett N. Morbidity and medication in a large population of individuals with Down syndrome compared to the general population. Dev Med Child Neurol. 2016;58:246-54. CrossRef

9. Kinnear D, Morrison J, Allan L, Henderson A, Smiley E, Cooper SA. Prevalence of physical conditions and multimorbidity in a cohort of adults with intellectual disabilities with and without Down syndrome: cross-sectional study. BMJ Open. 2018;8(2):e018292. CrossRef

10. Rall T. The U.S. also needs a centralized medical system. The Japan Times. Published May 12, 2020; accessed November 1, 2020. https://www.japantimes.co.jp/opinion/2020/05/12/commentary/ world-commentary/u-s-also-needs-centralized-medical-system/

11. National Down Syndrome Society. Healthcare guidelines. Accessed November 1, 2020. https://www.ndss.org/resources/ healthcare-guidelines/

12. Centers for Medicare \& Medicaid Services. ICD-10-CM official guidelines for coding and reporting. Updated January 1, 2021; accessed January 1, 2021. https://www.cms.gov/files/ document/2021-coding-guidelines-updated-12162020.pdf

13. Chenbhanich J, Wu A, Phupitakphol T, Atsawarungruangkit A, Treadwell T. Hospitalisation of adults with Down syndrome: lesson from a 10-year experience from a community hospital. J Intellect Disabil Res. 2019;63:266-76. CrossRef

14. Ram G, Chinen J. Infections and immunodeficiency in Down syndrome. Clin Exp Immunol. 2011;164:9-16. CrossRef

15. O'Leary L, Hughes-McCormack L, Dunn K, Cooper SA. Early death and causes of death of people with Down syndrome: a systematic review. J Appl Res Intellect Disabil. 2018;31:687-708. CrossRef

16. Santoro SL, Chicoine B, Jasien JM, et al. Pneumonia and respiratory infections in Down syndrome: a scoping review of the literature. Am J Med Genet A. 2021;185:286-99. CrossRef

17. National Down Syndrome Society. Sexuality. Last updated February 5, 2021; accessed November 3, 2020. https://www.ndss.org/ resources/sexuality/\#: : text=Men $\% 20$ and $\% 20$ women $\% 20$ with $\% 20$ Down,and $\% 20$ other $\% 20$ sexually $\% 20$ transmitted $\% 20$ infections

18. Eastgate G, Scheermeyer E, van Driel ML, Lennox N. Intellectual disability, sexuality and sexual abuse prevention - a study of family members and support workers. Aust Fam Physician. 2012;41:135-9.

19. Medina-Rico M, López-Ramos H, Quiñonez A. Sexuality in people with intellectual disability: review of literature. Sex Disabil. 2018;36:231-48. $\underline{\text { CrossRef }}$

20. Schmidt EK, Hand BN, Simpson KN, Darragh AR. Sexually transmitted infections in privately insured adults with intellectual and developmental disabilities. J Comp Eff Res. 2019;8:599-606. CrossRef

21. Guffroy A, Dieudonné Y, Uring-Lambert B, Goetz J, Alembik Y, Korganow A. Infection risk among adults with Down syndrome: a two group series of 101 patients in a tertiary center. Orphanet J Rare Dis. 2019;14(1):15. CrossRef

22. Malle L, Gao C, Hur C, Truong HQ, et al. Individuals with Down syndrome hospitalized with COVID-19 have more severe disease. Genet Med. 2021;23:576-80. CrossRef

23. Smith DS. Health care management of adults with Down syndrome. Am Fam Physician. 2001;64:1031-8.

24. Agency for Healthcare Research and Quality. Clinical Classification Software (CCS) for ICD-9-CM. Last modified March 6, 2017; accessed October 1, 2019. https://www.hcupus.ahrq.gov/toolssoftware/ccs/ccs.jsp

(C) 2022 Advocate Aurora Health, Inc. 